\title{
PIBID EM UMA ESCOLA DO CAMPO: UMA PROPOSTA DE EDUCAÇÃO AMBIENTAL PARA TRABALHAR PROBLEMAS REFERENTES ÀS DOENÇAS DE VEICULAÇÃO HÍDRICA
}

\author{
Cristina de Jesus Santos ${ }^{1}$ \\ Marcela Silva Brandão \\ Neila Carla Barreto Peixoto ${ }^{3}$ \\ Silvana do Nascimento Silva ${ }^{4}$
}

Resumo: o objetivo desse trabalho é problematizar o tema doenças de veiculação hídrica no contexto da comunidade local levando em consideração a falta de saneamento ambiental. Os bolsistas do Pibid Subprojeto Interdisciplinar de Educação Ambiental realizaram, em uma escola do campo da zona rural, uma experiência que consistiu no desenvolvimento de ações relacionadas aos problemas socioambientais vinculados à forma como a comunidade trata a água. As ações foram desenvolvidas em etapas, com visitas ao rio, discussão sobre saneamento ambiental e estudo do ciclo das doenças de veiculação hídrica. As discussões conduziram os educandos à identificação de fatores contribuintes para o estado de degradação dos corpos hídricos na comunidade e a importância dos serviços de saneamento para a qualidade de vida.

Palavras-chave: Educação Ambiental; Recursos Hídricos; Doenças.

\footnotetext{
1 Universidade Estadual do Sudoeste da Bahia. E-mail: criistinajs@gmail.com

2 Universidade Estadual do Sudoeste da Bahia. E-mail: marcelynhabrandao@gmail.com

${ }^{3}$ Centro Educacional Leur Lomanto. E-mail: neilabpeixoto@gmail.com

${ }^{4}$ Universidade Estadual do Sudoeste da Bahia. Email: siluesb@hotmail.com
} 


\section{Introdução}

Este relato de experiência apresenta as ações desenvolvidas em uma escola do campo, parceira do subprojeto interdisciplinar de Educação Ambiental do Programa Institucional de Bolsas de Iniciação à Docência (Pibid), da Universidade Estadual do Sudoeste da Bahia. O projeto vem enfocando estudos socioambientais, permitindo às comunidades o diálogo, a discussão e a construção de valores e atitudes em torno de seus problemas, em prol de uma sociedade sustentável.

A escola do campo tem o papel de contribuir para a produção de conhecimentos, de modo que os campesinos possam viver melhor no campo e, principalmente, para incluí-los na sociedade. Uma das formas de iniciar esta atitude é trabalhando assuntos que estejam presentes no cotidiano dos alunos, como as questões relacionadas à água (ZAKRZEVSKI, 2007).

Quando se trabalha em uma escola do campo é necessário que se faça um estudo etnográfico. A etnografia é um método de olhar mais próximo da comunidade e se baseia em uma experiência pessoal com participação, é também parte ou disciplina integrante da etnologia, que se ocupa com o estudo descritivo, classificatório e comparativo da cultura material, ou seja, dos artefatos encontrados nas diversas sociedades (PADILHA; CABRAL, s/d).

Com auxilio do estudo etnográfico, foi possível identificar e confirmar a problemática, sobre a falta de saneamento básico, que continua sendo um dos grandes problemas presentes nas comunidades da zona rural. As áreas rurais, que abrigam cerca de 30 milhões de pessoas em 8,8 milhões de domicílios, segundo a Pesquisa Nacional por Amostra de Domicílios (PNAD) 2009 são as mais carentes de infraestrutura de saneamento (FUNASA, 2011).

A água é um recurso essencial para diversos processos vitais, mas a eficácia de sua utilização depende de excelentes níveis de qualidade. No entanto, segundo Barros e Lucas (2013), são numerosos os casos de doenças de origem hídrica, relacionados a sua má qualidade, uma vez que os registros do Sistema Único de Saúde (SUS) mostram que 80\% das internações hospitalares do país se devem a doenças de veiculação hídrica, ou seja, doenças que decorrem de ingestão de água de qualidade imprópria para consumo humano.

Para Loureiro (2002), a Educação Ambiental (EA) é uma prática social, para a qual os processos ecológicos precisam estar vinculados aos sociais na leitura de mundo. O princípio fundamental dessa educação reconhece que somos seres biológicos, mas nos relacionamos com a natureza por meio de práticas sociais que nos formam ao longo da vida, como cultura, educação, classe social, instituições, família, etc.

É esse pressuposto que confere à EA o direito e o dever de promover discussões sobre a questão hídrica. Nesse sentido, Loureiro (2002) advoga que a EA deve problematizar a realidade, possibilitando uma compreensão contextualizada da realidade de vida, contribuindo assim para a construção de valores, habilidades e atitudes comprometidas com a sustentabilidade.

Revbea, São Paulo, V. 13, № 1: 227-239, 2018. 
A EA, na escola do campo, precisa estar vinculada aos interesses e às necessidades da comunidade. A inserção da EA nas escolas do campo deve proporcionar aos atores sociais condições de enfrentamento das questões socioambientais presentes na sua realidade, contribuindo para que os indivíduos se percebam como sujeitos ativos na apropriação e na elaboração do conhecimento, seja ele referente ao mundo natural ou ao cultural, e compreendam que são agentes de mudanças da realidade em que vivem, podendo de modo responsável e solidário contribuir para sua transformação (ZAKRZEVSKI, 2007).

Diante dessa perspectiva, a EA na escola do campo possibilita aos alunos uma compreensão contextualizada sobre as formas de se relacionar com o meio e a degradação do rio, bem como as doenças de veiculação hídrica na comunidade, além da importância dos serviços de saneamento ambiental na comunidade e, acima de tudo, proporciona a construção de uma visão crítica da responsabilidade social de todos para a construção de uma sociedade mais comprometida com a qualidade de vida, viabilizando a formação do indivíduo como cidadão consciente e agente transformador da sua realidade.

Nessa direção, o presente trabalho tem como objetivo geral possibilitar a problematização contextualizada sobre as questões socioambientais relacionadas à problemática da água e as doenças de veiculação hídrica na comunidade local. Logo após o levantamento dos problemas socioambientais presentes na comunidade, iniciamos na escola, a prática de discussões e atividades sobre o tema água e doenças de veiculação hídrica, sempre apontando exemplos da comunidade. Em decorrência do objetivo geral, foram definidos os seguintes objetivos específicos para nortear o trabalho a ser desenvolvido pelos educandos:

a) promover discussões sobre as questões socioambientais relacionadas ao problema da água e das doenças de veiculação hídrica dentro da realidade local;

b) proporcionar aos educandos o conhecimento sobre as formas de enfrentamento dos problemas existentes na comunidade.

\section{A escola do campo}

$\mathrm{Na}$ escola do campo, é necessário trabalhar de acordo com a realidade da comunidade e com suas necessidades. Entre os objetivos que precisam ser visados encontram-se o fortalecimento da identidade da população, seu envolvimento em debates que construam ou reconstruam seus pensamentos políticos e renovem seus conhecimentos sobre os movimentos sociais do campo e a orientação de seu povo na busca de soluções de acordo os seus direitos.

A escola do campo deve adotar uma educação que oriente suas práticas para a descentralização da escola, que não fique refém de sua lógica constitutiva, exatamente para poder ir bem além dela como projeto educativo.

revista brasileira educação ambiental 
$\mathrm{Na}$ história do campo brasileiro, ocorreram diversas lutas sociais pelo direito à educação, configuradas desde a realidade da luta pela terra, pelo trabalho, pela igualdade social, por condições de uma vida digna de seres humanos no lugar em que ela aconteça (CALDART, 2009).

O Movimento Nacional da Educação do Campo tem conquistado espaço no cenário sociopolítico nacional por meio de movimentos sociais e outras instituições ligadas a esses movimentos, os quais vêm desencadeando estratégias de mobilização e lutas pela efetivação do direito à educação.

Os meados da década de 1990 constituem o momento histórico em que começou a nascer o chamando de Movimento de Educação do Campo no Brasil (MUNARIM, 2008). A inserção do movimento na escola do campo tem por objetivo a transformação das condições de vida da população rural, abordando a reforma agrária, as políticas públicas e a expansão dos direitos humanos.

Neste atual momento, a escola precisa se aliar ao Movimento Nacional da Educação do Campo. Não basta ter essa conquista de inserção no movimento, é preciso que toda escola consiga trabalhar em sala de aula na luta pela integridade da identidade dos campesinos (MARCCOCIA; POLLON, 2014).

A EA, em conjunto com a Educação do campo, pode fomentar essa luta, principalmente quando na escola os conteúdos possam ser contextualizados com a realidade local. Um exemplo interessante, nesse sentido, é o problema do saneamento ambiental que afeta toda uma comunidade e, por isso, é considerado como problema de ordem coletiva.

\section{O saneamento ambiental é um problema coletivo}

Segundo a Funasa (2011), nem só de obras físicas são compostas as ações relacionadas ao saneamento básico. As equipes de Educação têm um papel fundamental na promoção da saúde da população. É preciso um trabalho de mobilização e conscientização, em busca da melhoria e qualidade de vida das comunidades, também como a inclusão social e a sustentabilidade.

Os protagonistas do processo de criação da educação do campo são os "movimentos sociais camponeses em estado de luta" (CALDART, 2009, p.35). A escola deve contribuir com os movimentos e orientar a população sobre os seus direitos. Isto se torna bem mais fácil quando a escola conhece as características da comunidade e seus problemas. Para isso, é necessário inserir em sala de aula temas sobre os assuntos que podem ser considerados como dificuldades enfrentadas por ela, de maneira que possa trabalhar adequadamente com a população para uma transformação em desenvolvimento.

Quando a comunidade conhece os seus direitos torna-se mais eficaz 
Mais de um bilhão de habitantes na Terra não têm acesso à habitação segura e a serviços básicos, embora todo ser humano tenha direito a uma vida saudável e produtiva, em harmonia com a natureza. No Brasil, as doenças resultantes da falta ou de um inadequado sistema de saneamento, especialmente em áreas pobres, têm agravado o quadro epidemiológico (BRASIL, 2006, apud RIBEIRO; ROOCKE, 2010, p.2).

Segundo Guimarães et al. (2007), a oferta do saneamento abrange os seguintes serviços: abastecimento de água às populações, com a qualidade compatível com a proteção de sua saúde e em quantidade suficiente para a garantia de condições básicas de conforto, e coleta, tratamento e disposição ambientalmente adequada e sanitariamente segura de águas residuais (esgotos sanitários, resíduos líquidos industriais e agrícola entre outros serviços).

A maioria dos problemas de saneamento está relacionada ao ambiente em que a população vive (RIBEIRO; ROOCKE 2010). Assim sendo, o processo saúde versus doença não deve ser entendido como uma questão puramente individual e sim como um problema coletivo (GUIMARÃES et al., 2007).

Se não houver tratamento, a água, tão necessária à vida do ser humano, pode ser motivo de contágio de doenças. Existem vários tipos de doenças de veiculação hídrica, mas as principais são: amebíase, giardíase, gastroenterite, febres tifoide e paratifoide, hepatite infecciosa e cólera.

\section{Doenças de veiculação hídrica}

As doenças de veiculação hídrica são doenças provocadas devido à ingestão direta de água contaminada, em geral, em locais onde não há sistema de abastecimento de água tratada (SÃO PAULO, s/d) e os grupos populacionais fazem uso de minas, poços, bicas ou, então, utilizam água mineral de fontes contaminadas.

Muitas vezes, pode acontecer um surto de doença relacionada à ingestão de água contaminada ou saneamento deficiente. O surto é causado por ingestão de água quando duas ou mais pessoas apresentam a mesma doença, após consumirem água contaminada da mesma origem (SÃO PAULO, $\mathrm{s} / \mathrm{d}$ ). A água tratada e os equipamentos de saneamento (banheiros, latrinas, fossas) e comportamentos adequados de higiene são importantes para a redução das doenças relacionadas a saneamento e higiene.

Outro importante fator de risco ocorre quando o esgoto produzido pelas áreas urbanas e periféricas e de áreas de invasão populacional é jogado em rios, córregos, represas, sem tratamento prévio. As populações do entorno, ao 
fazer uso dessa água, estão expostas a várias doenças que podem ser adquiridas por ingestão ou contato, em atividades ocupacionais ou de lazer.

O controle de transmissão das doenças, além da intervenção em saneamento e dos cuidados médicos, completa-se quando é promovida a educação sanitária, adotando-se hábitos higiênicos (BOVOLATO, 2010).

A educação deve ser um fator de promoção e proteção à saúde, bem como estimular a criação de estratégias para a conquista dos direitos de cidadania (BRASIL, 2008). Devem ser inseridos no ambiente escolar debates que levem o aluno à reflexão sobre a higiene, saúde e condição de vida.

\section{Metodologia}

O presente trabalho foi resultado das ações desenvolvidas seguindo os parâmetros do Subprojeto de Educação Ambiental do Pibid-Uesb, em uma escola do campo, localizada no interior da Bahia, nas turmas de sexto, sétimo, oitavo e nono anos do Ensino Fundamental, essa pesquisa foi realizada entre maio de 2014 a julho de 2015.

A metodologia a ser utilizada para o desenvolvimento deste está fundamentada em metodologias participativas e baseia no programa Escola Sustentável instituído pela Resolução CD/FNDE no 18/2013.

A participação deve ser um eixo estruturante das práticas de Educação Ambiental e, considerando o quadro de agravamento cotidiano da crise ambiental, esta representa um instrumento essencial para a transformação das relações entre sociedade e ambiente (JACOBI, 2005).

As atividades foram desenvolvidas em quatro etapas (Quadro 1):

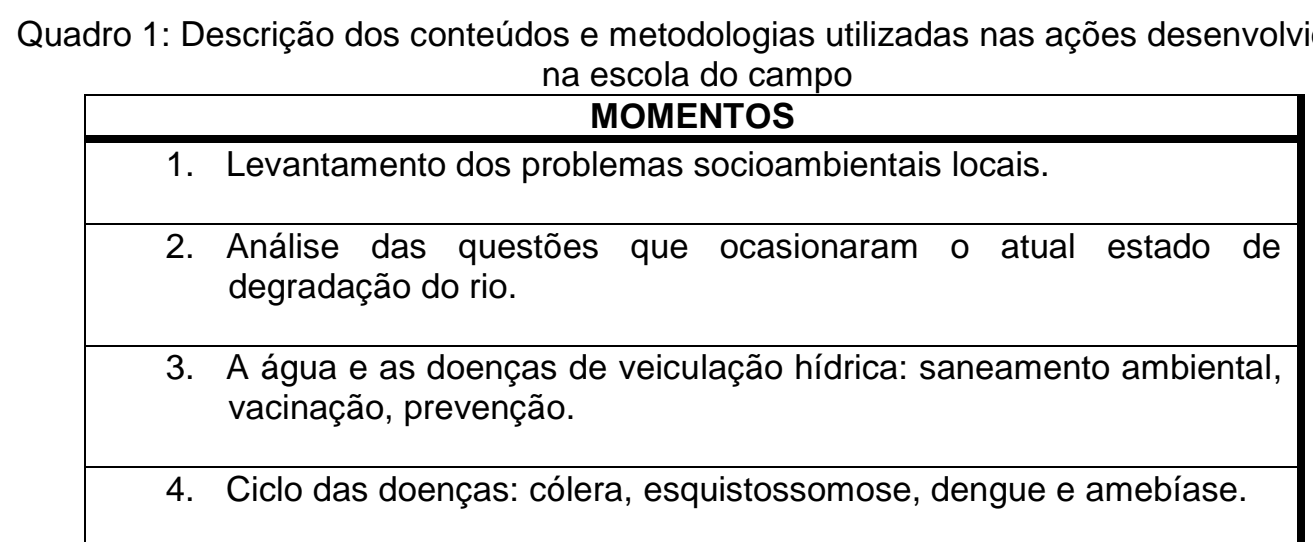

Fonte: acervo do Pibid Interdisciplinar EA. 


\section{Levantamento dos problemas socioambientais locais.}

Nesta fase, os estudantes campesinos, em sala de aula descreveram os problemas que os afligem em um único cartaz por grupo, em que foram convidados a apresentar no cartaz por meio de desenhos e frases, tudo aquilo de que não gostam, que os incomodem ou que atrapalham a qualidade de vida. Em seguida, os alunos, com o mesmo cartaz, apontaram ações que já realizaram ou que vão passar a fazer, à medida que reconhecem os impactos causados no ambiente em que vivem como consequência da ação humana.

2. Análise das questões que ocasionaram o atual estado de degradação do rio.

Foi realizado uma visita à comunidade, mais especificamente a que habita às margens de um rio próximo a escola, realizando observações e questionamentos. Foi solicitado aos alunos que perguntassem aos seus pais histórias sobre o rio e compartilhasse com seus colegas durante a visita.

3. A água e as doenças de veiculação hídrica: saneamento ambiental, vacinação, prevenção.

Por meio de uma aula expositiva e dialogada, com discussões sobre as temáticas referentes à água e as doenças na comunidade.

4. Ciclo das doenças: cólera, esquistossomose, dengue e amebíase.

Por meio da montagem de quebra-cabeças sobre os ciclos das doenças de veiculação hídrica: esquistossomose, dengue e amebíase, ocorreram à socialização das questões pertinentes às doenças, bem como as formas de contaminação e prevenção.

No decorrer da apresentação dos resultados os estudantes serão identificados pela letra $E$, e seguida por numeração em ordem crescente $(1,2$, 3...), de forma a garantir o anonimato.

\section{Resultados e discussão}

Com base na atividade realizada no primeiro encontro, com 0 levantamento dos problemas socioambientais locais, os alunos conseguiram trazer um pouco de sua realidade para o contexto escolar, contribuindo assim para a construção do conhecimento, a partir da socialização dos seguintes temas: poluição do rio, desmatamento, poluição do ar por meio de queimadas, caça de animais, lixo nas ruas.

Vários problemas foram levantados pelos alunos, como "peixes mortos no rio" (E1), "caça de pássaros na localidade" (E2), "queimadas de árvores na comunidade" (E3). 
Nessa interação, os alunos conseguiram o que Zakrzevski (2007) propõe para as escolas do campo: uma EA capaz proporcionar meios para que os atores sociais identifiquem, analisem, compreendam e resolvam os problemas dentro da sua realidade.

A poluição do rio foi um dos problemas de maior preocupação dos alunos. A população local não possui saneamento ambiental: assim, todo seu lixo é lançado no rio, que passa ao fundo das casas. Para dirimir os conflitos ambientais, com certeza, é importante canalizar valas e córregos, coletar resíduos domésticos, selecionar os detritos recicláveis (RUSCHEINSKY, 2004).

Os usuários de serviços de água e esgoto têm, desde 2007, uma série de direitos assegurados pela Lei do Saneamento Básico. A legislação federal prevê a universalização dos serviços de abastecimento de água e tratamento da rede de esgoto para garantir a saúde dos brasileiros (BRASIL, 2012). Neste caso, a escola deve auxiliar a comunidade para cobrar da empresa responsável pela distribuição de água à instalação do saneamento básico.

No segundo encontro, com base nas observações e questionamentos formulados pela comunidade na visita ao rio (Figuras 1 e 2), os alunos tiveram a oportunidade de observar e analisar os problemas da comunidade relacionados à forma com que estabelecemos relações com o meio ambiente $\mathrm{e}$ o descaso político.

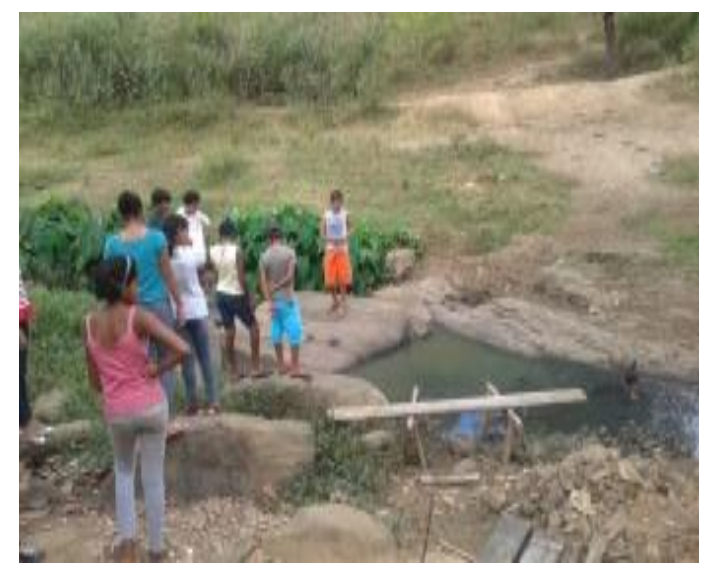

Figura 1: visita do Pibid e estudantes Fonte: acervo do Pibid Interdisciplinar EA.

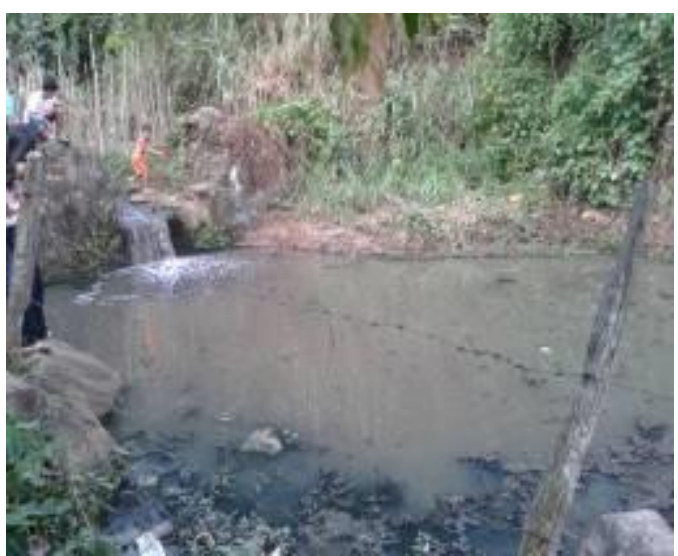

Figura 2: crianças brincando no rio.

Fonte: acervo do Pibid Interdisciplinar EA. 


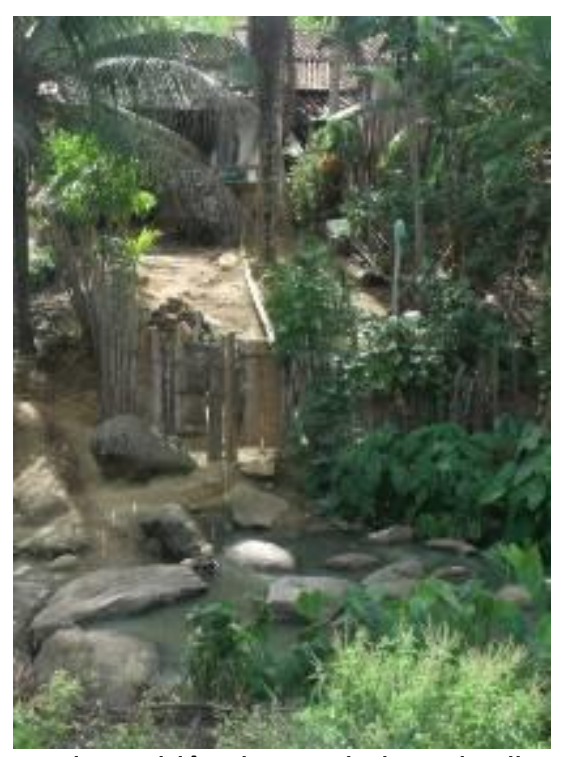

Figura 3: Esgoto da residência sendo jogado diretamente no rio

Fonte: acervo do Pibid Interdisciplinar EA.

Conforme Blikstein (2007), a EA é um excelente campo para tentar novas abordagens de ensino e aprendizagem, pois pode envolver atividades fora dos muros da escola e pode aprofundar questões que estão no cotidiano dos alunos.

No terceiro momento, a partir da observação sobre as características da comunidade, observamos a necessidade de abordar, por meio de aula expositiva e dialogada, os temas água, doenças de veiculação hídrica, importância dos serviços de saneamento ambiental e prevenção. Os alunos conseguiram relacionar o conhecimento apresentado com a realidade local. Socializaram diversas questões pertinentes à situação hídrica na localidade, como "o abastecimento de água depende de outra localidade", "os esgotos das casas são lançados diretamente no rio", "o lixo das casas que acaba chegando ao rio".

Diante da situação hídrica vigente na comunidade, os alunos puderam perceber a necessidade de saneamento que é um direito básico para garantir a qualidade de vida, embora tenham a percepção de que nada vai mudar por causa da situação política da localidade.

A atividade proporcionou uma boa reflexão sobre o que ocorre nos locais com saneamento básico deficiente (falta de água tratada e/ou de rede de esgoto ou de alternativas adequadas para a deposição dos dejetos humanos): as doenças podem ocorrer devido à contaminação da água por esses dejetos ou pelo contato com esgoto despejado nas ruas ou nos córregos e rios.

Para Zavaresky (2007) a inserção da EA nas escolas do campo tem como grande desafio contribuir para recriar os vínculos de pertencimento dos sujeitos, para que estes se reconheçam como integrantes de uma comunidade e reconstruam a sua identidade com o campo, com o local em que vivem, pois, no momento em que os sujeitos sentem-se pertencentes a um determinado 
território, eles possuem sentimentos que Ihes possibilitam comprometerem-se com a realidade socioambiental.

Além disso, os educandos perceberam como o descarte inadequado do lixo compromete a qualidade do ambiente e consequentemente a qualidade de vida na comunidade. Para Trajber (2007), o desafio proposto para a EA é compor uma concepção crítica que aponte para a descoberta da qualidade de vida para as pessoas.

Houve também a socialização das doenças de veiculação hídrica, como cólera, dengue, esquistossomose, amebíase. Durante essa atividade, com base nos questionamentos, pôde-se constatar que os alunos não conheciam algumas doenças nem a dimensão dos problemas relacionados à má qualidade da água.

$\mathrm{Na}$ última atividade, com a montagem do quebra-cabeça e com apresentação de trabalho que fizeram sobre o ciclo das doenças relacionadas à água como a dengue, amebíase e esquistossomose, perceberam-se o envolvimento e a participação dos alunos, e como eles conseguiram identificar e pensar as doenças no seu cotidiano de acordo com suas experiências (Figuras 4 e 5). Do ponto de vista da EA crítica, percebe-se a importância em conhecer a dimensão da comunidade, sendo necessário trabalhar com os alunos, temas do seu cotidiano, na busca de resolução dos problemas enfrentados por eles, estimulando o senso crítico para a percepção e posicionamento relativamente aos problemas do descaso com o saneamento e o tratamento da água.
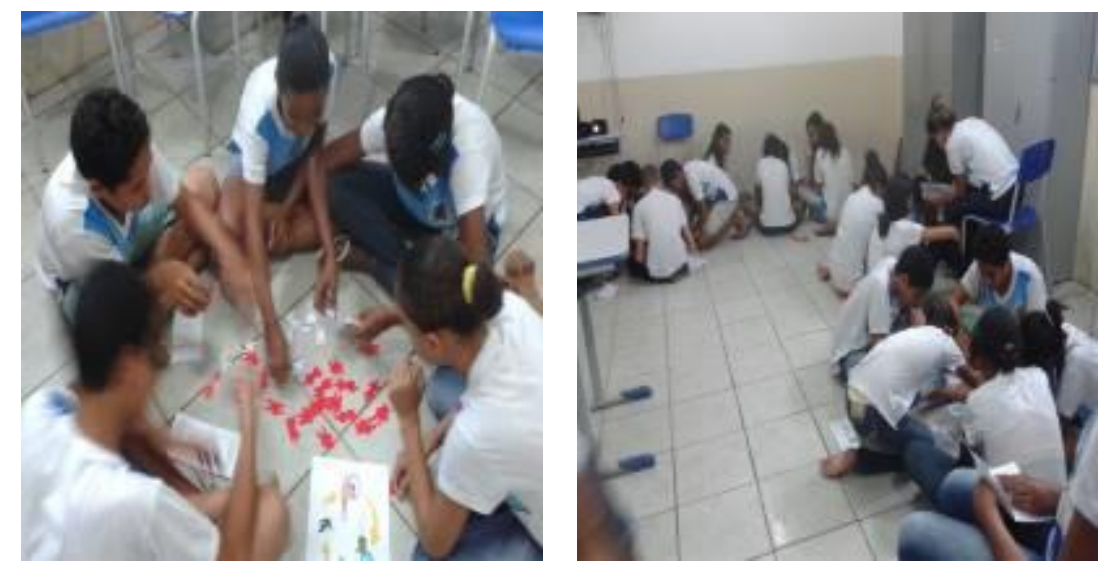

Figuras 4 e 5: montagem do quebra-cabeça e elaboração da apresentação dos ciclos das doenças de veiculação hídrica.

Fonte: acervo do Pibid Interdisciplinar EA.

Sendo a falta de saneamento ambiental, um dos problemas de maior destaque nas observações da comunidade e discussões com os alunos. Uma tentativa de minimizar este problema é inserir na comunidade discussões referentes às consequências da falta dos serviços de saneamento ambiental em detrimento da qualidade de vida. 
É preciso mostrar para a comunidade como eles podem conquistar estes serviços e não realizá-los pelos responsáveis por sua construção. Primeiro levar a reflexão, apresentando os pontos positivos e negativos, segundo, apresentar o percurso da água na comunidade hoje e como pode ser caso ocorra a mudança, além de abordar as consequências da falta destes serviços para a saúde e o meio ambiente.

Guimarães (2007) afirma, que há uma necessidade cada vez maior de se trabalhar a questão ambiental no processo educativo de maneira a desvelar a origem dos problemas socioambientais, que estão além das salas de aula, estão na realidade cotidiana da vida social de cada um.

\section{Conclusões}

Um aspecto inquestionável ficou claro para os futuros professoresbolsistas do Pibid: percebeu-se a importância da inserção de projetos no contexto escolar para proporcionar aos alunos condições de enfrentamento dos problemas do seu cotidiano, o que muitas vezes não tem seu espaço durante as aulas.

A EA deve estar comprometida com a mudança de ações dos atores sociais, criando possibilidades para conduzir o aluno à transformação de si próprio e consequentemente, habilitando-o para transformar o meio. Projetos desta natureza, no contexto escolar, levam os educandos do campo a compreenderem a EA, além de produzirem uma conscientização voltada para o plantio de árvores e para a reciclagem. A educação ambiental precisa estar presente nas ações e nas relações humanas para a construção de uma sociedade comprometida com a qualidade de vida.

O desenvolvimento deste trabalho foi de suma importância no sentido de promover inquietações dos sujeitos envolvidos naquela realidade sobre os problemas socioambientais e o papel de cada um diante das problemáticas referentes às doenças de veiculação hídrica. Por meio das análises, foi possível perceber a precariedade de serviços de saneamento básico e as limitações de informações que contribua para melhorias de vida das pessoas inseridas na comunidade rural.

O enfrentamento dos problemas socioambientais tem se apresentado como um desafio. No entanto, para que os alunos desenvolvam uma postura crítica e atuante sobre os problemas socioambientais, cabe aos educadores, como colaboradores na formação de indivíduos, desenvolverem projetos que os levem a compreender o meio em que vivem e a agir para a transformação da sociedade.

As experiências vivenciadas no Pibid nos têm direcionado para refletir o verdadeiro sentido de ser educador. Esse contato maior com a escola, antes de exercer a profissão, nos possibilita conhecer o contexto escolar, os desafios e as perspectivas, a realidade de vida dos alunos. Tudo isso nos levou a ter um cuidado ao planejar as ações, a pensar no contexto social dos alunos e 
proporcionar a eles condições de enfrentamento dos problemas existentes na sociedade, com posturas responsáveis e éticas para os problemas que porventura virão.

Esse trabalho contribuiu para que as discussões sobre os problemas relacionados com a situação hídrica global perpassassem os muros da universidade, permitindo, assim, o diálogo com outros espaços de formação, como a escola e a comunidade, buscando superar os desafios e entraves acerca dos problemas socioambientais locais que, na maioria das vezes, não são debatidos durante as aulas. Enfim, o que se busca é uma formação de qualidade para todos os sujeitos envolvidos na questão, através de inquietações, reflexões e ações em prol do bem comum.

\section{Agradecimentos}

A Coordenação de Aperfeiçoamento de Pessoal de Nível Superior (CAPES), pelas bolsas disponibilizadas as autoras desse artigo, enquanto bolsistas do Pibid Interdisciplinar EA; à Universidade Estadual do Sudoeste da Bahia e o Centro Educacional Leur Lomanto pela parceria desenvolvida.

\section{Referências}

BARROS, I.P. LUCAS, A.A. Doenças de veiculação hídrica na sub-bacia do rio Ganhamoroba, Maruim-Sergipe. Anais do VI Encontro de Recursos Hídricos. Aracaju. 2013.

BLIKSTEIN, P. As novas tecnologias na educação ambiental: instrumentos para mudar o jeito de ensinar e aprender na escola. In: MELLO, S.S.; TRAJBER, R. (Coord.). Vamos cuidar do Brasil: conceitos e práticas em educação ambiental na escola. Brasília: UNESCO, P. 155-165, 2007.

BOVOLATO, L.E. Saneamento Básico E Saúde - / Revistas escritas UFT ARAGUAINA, Tocantis, v. 2,2010.

BRASIL, Lei do saneamento basico garante direitos aos usuarios de servicos de agua e esgoto. Portal da Transparencia, 2012. Disponível em: http://www.brasil.gov.br/cidadania-e-justica/2012/04/lei-do-saneamento-basicogarante-direitos-aos-usuarios-de-servicos-de-agua-e-esgoto / Acesso junho de 2015.

CALDART, R.S. Educação do Campo: Notas para uma Análise de Percurso. Porto Alegre, Trab. Educ. Saúde, Rio de Janeiro, v. 7 n. 1, p. 35-64, mar./jun.2009

FUNASA (2011). Fundação Nacional de Saúde. Boletim informativo Saneamento rural, no edição 10, 2011.

GUIMARÃES, C.S et al. Saneamento Básico. UFRRJ- RJ, 2007 Disponível em:<http://www.ufrri.br/institutos/it/deng/leonardo/downloads/APOSTILA/Apostil a\%20IT\%20179/Cap\%201.pdf> Acesso em julho 2015. 
JACOBI, P.R. Educação Ambiental: o desafio da construção de um pensamento crítico, complexo e reflexivo. Educação e Pesquisa, São Paulo, v. 31, n. 2, p. 233-250, maio/ago. 2005

LOUREIRO, C.F. Educação Ambiental e Movimentos Sociais na Construção da Cidadania Ecológica e Planetária. Educação ambiental: repensando o espaço da cidadania. São Paulo, Cortez, 2 ed. P. 256, 2002.

MARCOCCIA, P.C; POLON, S. A. Escolas públicas localizadas no campo e o movimento nacional da educação do campo: quais aproximações? Anais do Xo ANPED SUL, Florianópolis, 2014.

MUNARIM, A. Movimento Nacional De Educação Do Campo: Uma Trajetória Em Construção. Anais da 31ㄹ Reunião Anual da Associação Nacional de PósGraduação e Pesquisa em Educação. Caxambu/MG,outubro, 2008.

PADILHA; CABRAL. Significado de Etnografia. significados.com.br. Disponível em <https://www.significados.com.br/etnografia/> Acesso em março, 2018.

RIBEIRO, J.W; ROOKE. J.M.S. Saneamento básico e sua relação com meio ambiente e a saúde pública. Trabalho de conclusão de Curso - Colegiado do Curso de Especialização em Análise Ambiental da Universidade Federal de Juiz de Fora. Disponível em: $<$ http://www.ufjf.br/analiseambiental/files/2009/11/TCC-

SaneamentoeSa\%C3\%BAde.pdf>

RUSCHEUNSKY, A. Atores Sociais E Meio Ambiente: A Mediação Da Ecopedagogia Identidade da Educação Ambiental Brasileira, Brasília, Ministério do Meio Ambiente. Diretoria de Educação Ambiental; Philippe Pomier Layrargues (coord.). - Brasília: Ministério do Meio Ambiente, 2004.

SÃO PAULO. Secretaria de Estado da Saúde de São Paulo. Doenças Relacionadas à Água ou de Transmissão Hídrica - Perguntas e Respostas e Dados Estatísticos - Informe Técnico. Divisão de Doenças de Transmissão Hídrica e Alimentar. Centro de Vigilância Epidemiológica. São Paulo . S/A.

TRAJBER, R. Cidadania e consumo sustentável: nossas escolhas em ações conjuntas. In: MELLO, S.S.; TRAJBER, R. (Coord.). Vamos cuidar do Brasil: conceitos e práticas em educação ambiental na escola. Brasília: UNESCO, P. 143-150, 2007.

ZAKRZEVSKI, S. A educação Ambiental nas escolas do campo. In: MELLO, S.S.; TRAJBER, R. (Coord.). Vamos Cuidar do Brasil: Conceitos e práticas em educação ambiental na escola. Brasília: UNESCO, P. 199-206, 2007 